Methods: This is a retrospective cohort study based on data from three databases. Daily HFx incidence was calculated using discharge data from the hospital of Alcorcón for the period 2000-2015. Daily weather conditions were compiled from records of the national meteorological station (AEMET). Daily air pollutant levels $\left(\mathrm{mcg} / \mathrm{m}^{3}\right)$ were calculated from data from the Ministry of Environment for the Madrid Community: sulfur dioxide $\left(\mathrm{SO}_{2}\right)$, nitrogen monoxide (NO), nitrogen dioxide $\left(\mathrm{NO}_{2}\right)$, ozone $\left(\mathrm{O}_{3}\right)$ and particulate matter in suspension $<2.5 \mu \mathrm{m}\left(\mathrm{PM}_{2.5}\right)$ and $<10 \mu \mathrm{m}\left(\mathrm{PM}_{10}\right)$, for the same period. Pollutant concentrations were categorised into quartiles (Q1 to Q4, lowest to highest). Associations between HFx incidence and air pollutant levels were examined through Ggeneralized Additive Models (GAM) at a daily level with Poisson link function. Models were adjusted for a penalised spline function of time.

Main outcome measures: Daily hospital admissions for hip fracture.

Results: HFx incidence showed a direct association with $\mathrm{NO}, \mathrm{NO}_{2}, \mathrm{PM}_{2.5}$ and $\mathrm{PM}_{10}$ and inverse association with $\mathrm{O}_{3}$ levels. Incidence rate ratios for Q1vsQ2, Q1vsQ3 and Q1vsQ4 respectively were: 1.171 (1.103-1.244), 1.245 (1.173$1.322)$ and $1.331(1.253-1.414)$ for NO; 1.057 (0.996-1.122), 1.185 (1.116$1.259)$ and $1.276(1.199-1.357)$ for NO2; $1.028(0.943-1.12), 1.092$ (1.006$1.185)$ and $1.146(1.049-1.253)$ for $\mathrm{PM}_{2.5} ; 1.083$ (1.016-1.155), 1.099 (1.034$1.168)$ and 1.213 (1.136-1.294) for $\mathrm{PM}_{10}$; and 0.975 (0.914-1.04), 0.868 (0.815$0.924)$ and $0.814(0.765-0.867)$ for $\mathrm{O}_{3}$. These associations persisted when the models were corrected for season, day of the week and weather conditions. When participants were stratified by age and sex, associations persisted only in women older than 75 years.

Conclusions: A short-term effect was observed of several indicators of air pollution on hip fracture incidence. This is the first study that finds this association.

Disclosure of Interest: None declared

DOI: 10.1136/annrheumdis-2018-eular.1515

\section{OP0069 THE RELATIONSHIP BETWEEN ESTIMATED BONE STRENGTH BY FINITE ELEMENT ANALYSIS AT THE PERIPHERAL SKELETON TO AREAL BMD AND TBS AT LUMBAR SPINE IN ADULTS}

J.C. Alvarenga ${ }^{1}$, S. Boyd ${ }^{2}$, R. Pereira ${ }^{1}$. ${ }^{1}$ Faculty of Medicine/University of Sao Paulo, Sao Paulo, Brazil; ${ }^{2}$ McCaig Institute for Bone and Joint Health, University of Calgary, Calgary, Canada

Background: Bone strength, estimated by finite element (FE) analysis based on high resolution peripheral quantitative computed tomography (HR-pQCT) images is an important contributor to understanding risk of fracture. However, it is a peripheral device and cannot be evaluated in vivo at lumbar spine L1-L4

Objectives: The aim of this study was to investigate if the axial bone quality can be predicted by strength measurements of peripheral bone.

Methods: Peripheral bone microarchitecture, areal bone mineral density (aBMD) and trabecular bone score (TBS) were measured in adults individuals ( $n=262,60$ years and older; $63 \%$ women). Stiffness and failure load were estimated by FE analysis at HR-pQCT images at radius and tibia. Areal BMD and TBS were measured by dual energy X-ray absorptiometry (DXA) at L1-L4. Correlations between peripheral and axial data were estimated for each gender adjusted by age, weight, and height.

Results: Areal BMD L1-L4 resulted in weak to moderate significant correlations with stiffness and failure load at radius (women: $R^{2}=0.178, p<0.05$ and $R^{2}=0.187$, $p<0.001$, respectively; men: $R^{2}=0.454$ and $R^{2}=0.451, p<0.001$, respectively) and at tibia (women: $R^{2}=0.211$ and $R^{2}=0.216, p<0.001$, respectively; men: $\mathrm{R}^{2}=0.488$ and $\mathrm{R}^{2}=0.502, \mathrm{p}<0.001$, respectively). TBS showed a very weak or no correlation with stiffness and failure load at radius (women: $R^{2}=0.148$ and $R^{2}=0.150, p<0.05$, respectively; men: $R^{2}=0.108$ and $R^{2}=0.106, p<0.05$, respectively) and at tibia (women: $R^{2}=0.146$ and $R^{2}=0.150, p<0.05$, respectively; men: $\mathrm{R}^{2}=0.072$ and $\mathrm{R}^{2}=0.078$, respectively).

Conclusions: These data suggest that aBMD L1-L4 was better explained by peripheral bone strength characteristics than the TBS, mainly in men and tibia is generally the site with a better relationship.

Disclosure of Interest: None declared

DOI: 10.1136/annrheumdis-2018-eular.3978
WEDNESDAY, 13 JUNE 2018

\section{New drugs - new perspectives: clinical and regulatory issues concerning biosimilars}

\section{OP0070-HPR IS PATIENTS' SATISFACTION WITH BEING SWITCHED TO A BIOSIMILAR MEDICATION ASSOCIATED WITH THEIR LEVEL OF HEALTH LITERACY? RESULTS FROM A NORWEGIAN USER SURVEY}

M. Cvancarova Småstuen ${ }^{1}$, M. Brandvold ${ }^{2}$, R. Andenæs ${ }^{1} .{ }^{1}$ Public Health, Oslo Metropolitan University; ${ }^{2}$ Intensive Care, Oslo University Hospital, Oslo, Norway

Background: Economically motivated switching to biosimilar medication has been practiced in Norway since March 2016. There are several studies comparing the efficacy, safety and immunogenicity of biosimilars, however no studies have yet described patients' experiences and attitudes towards economically motivated switching.

Objectives: The aim of this study was to describe patients' experiences regarding being switched to an alternative medication (the switch) and further to investigate possible associations between such switching and health literacy.

Methods: Potential users of Etanercept or Infliximab were asked to participate using three patients' interest associations. Data from this convenience sample was collected using a web-survey in January 2017. Attitudes and experiences with a possible switch to an alternative medications were assessed using severa questionnaires. In addition, data on gender, age and marital status were collected. Patients' experiences, attitudes and satisfaction were assessed using a selfdeveloped questionnaire. In addition, health related literacy was measured using The Health Literacy Questionnaire a multi-dimensional validated questionnaire. We used three domains covering patients' ability to actively engage with health care providers (Scale 6), ability find good health information (Scale 8) and understanding health information well enough to know what to do (Scale 9). Data were analysed using multiple logistic regression and the results expressed as odds for being satisfied with the switch.

Results: Of all included responders $(n=290), 155$ reported being switched to a biosimiar medication in 2016. Median age was 51 years, range $20-74$. The majority of responders were females, $61 \%(n=176)$ and more than half $(51 \%)$ completed higher education. Over $80 \%$ of those who were switched (economically motivated switch to a biosimilar drug) were neutral or satisfied with their new medication. Patients who were dissatisfied with being switched had lower levels of health related literacy compared to patients who were satisfied. Further, older patients reported more often being satisfied compared to younger patients. Only $14 \%$ reported that they were involved when a decision to being switched was made, male patients significantly more often compared to female patients $(p=0.02)$. Selfassessed good health was strongly associated with higher probability of being satisfied with the switch, only 9/74 patients who reported bad health also reported being satisfied. When adjusted for age and self-assessment of one's own health scales 6 and 8 but not scale 9 , were significantly associated with higher odds for being satisfied with being switched (OR=2.5, 95\% Cl: [1.2 to 5.2] and $\mathrm{OR}=2.7$, $95 \% \mathrm{Cl}:[1.2$ to 5.9$]$, for scale 6 and 8 , respectively).

Conclusions: A great majority of patients reported being satisfied with being switched to a cheaper biosimilar medication, however, almost one in five $(19 \%)$ reported being dissatisfied. Our findings suggest that patients' attitudes and level of satisfaction are associated with being given sufficient and necessary information concerning their health.

Acknowledgements: We would like to thank Pfizer for providing us with unrestricted grant to finantially support this project.

Disclosure of Interest: M. Cvancarova Småstuen Grant/research support from Grant from Pfizer, M. Brandvold: None declared, R. Andenæs: None declared DOI: 10.1136/annrheumdis-2018-eular.5993

WEDNESDAY, 13 JUNE 2018

\section{Movement in musculoskeletal pain; from risk to} management

\begin{tabular}{l|l}
\hline OP0071 & THE PREVALENCE OF PAIN FLARES: IMPACT OF \\
DEFINITION &
\end{tabular}

A.L. Beukenhorst $^{1}$, J. McBeth ${ }^{1}$, J.C. Sergeant ${ }^{2}$, D.M. Schultz ${ }^{3}$, W.G. Dixon ${ }^{1}$. ${ }^{1}$ Arthritis Research UK Centre for Epidemiology; ${ }^{2}$ Centre for Biostatistics; ${ }^{3}$ Centre for Atmospheric Science, University of Manchester, Manchester, UK

Background: Rapid acute pain exacerbations, colloquially called pain flares, affect quality of life and are a key driver for patients to seek healthcare. There is no standardised definition of pain flare. ${ }^{1}$ Daily collection of patient-reported symptoms with mobile technology enables monitoring pain flares in real-time. The 